\title{
Expanded carrier screening in gamete donors of Venezuela
}

\author{
Maria Teresa Urbina ${ }^{1}$, Isaac Benjamin ${ }^{1}$, Randolfo Medina ${ }^{1}$, José Jiménez ${ }^{1}$, Laura Trías $^{1}{ }$, Jorge Lerner ${ }^{1}$ \\ ${ }^{1}$ Unifertes Fertility Unit, Caracas, Venezuela.
}

Presented at Taller General de la Red Latinoamericana de Reproducción Asistida 2017, Buenos Aires, Argentina.

\begin{abstract}
Objective: To discuss the implications of expanded genetic carrier screening for preconception purposes based on our practice.

Methods: One hundred and forty-three potential gamete donors aged 20-32 years old ( $\mu=24,127$ females and 16 males), signed informed consent forms and were selected according to the REDLARA guidelines. Blood or saliva samples were examined by one of these genetic carrier screening methods: Genzyme screening for Cystic Fibrosis (CF), Fragile $X$ and Spinal Muscular Atrophy (SMA); Counsyl Universal panel or Recombine Carrier Map.

Results: Genotyping results for all donors were analyzed; $41 \%(58 / 143)$ of donors were identified as carriers for at least one condition. We found a carrier frequency of $1 / 24$ for $C F, 1 / 72$ for SMA and $0 / 120$ for Fragile $X$ syndrome. Among the high-impact most prevalent conditions in our study (Carrier Map group) were: 21-Hydroxilase-Deficient Congenital Nonclassical Adrenal Hyperplasia (1/8), Factor V deficiency (1/12), Hemochromatosis: Type 1: HFE Related (1/12), Short Chain Acyl-CoA (1/14) and MTHFR deficiency 1/3 (39\%).

Conclusions: The rate of gamete donors identified as carriers of at least one condition was $41 \%$, which supports the offering of expanded carrier screening to our population. Studies in Latin American populations could help customize screening panels. The ART patient population has a unique opportunity to be offered expanded carrier screening and appropriate counseling, to make its best-informed decisions.
\end{abstract}

Keywords: Expanded carrier screening, CF, SMA

\section{INTRODUCTION}

Gene-by-gene carrier screening has been available for years to patients with increased genetic risk and considering pregnancy (for example, Ashkenazi Jewish patients). Expanded genetic carrier screening (ECS) has been developed for many disorders, with low costs, enabling patients to consider several reproduction options. Guidelines regarding ethnicity and population-based genetic screening have been published by the American College of Obstetricians and Gynecologists (ACOG), the American College of Medical Genetics (ACMG), National Society of Genetic Counselors, Perinatal Quality Foundation and Society for Maternal-Fetal Medicine, Society of Obstetricians and Gynecologists of Canada, Canadian College of Medical Geneticists and others (ACOG, 2017a,b; Grody et al. , 2013; Edwards et al., 2015; Wilson et al., 2016). Guidelines for gamete carrier donors have also been published by the American Association of Reproductive Medicine (ASRM)/ Society for Assisted Reproductive Technology (SART) (The Practice Committee of the American Society for Reproductive Medicine \& the Practice Committee of the Society for Assisted Reproductive Technology, 2013) and Red Latino Americana de Reproducción Asistida (REDLARA, 2015) among others.
According to the ACOG, ethnic-specific, pan-ethnic, and ECS are acceptable strategies for preconception and prenatal carrier screening. ECS, enables patients to make informed decisions to plan pregnancy based on their personal values (ACOG, 2017a,b). The ACOG recommends offering ECS to every woman, regardless of ethnicity or family history (ACOG, 2017a,b). Other professional associations consider that ECS is still expensive in some countries, and produces anxiety to the patients if they cannot afford it. Because those are rare diseases and do not cause significant health impairments, screening could be unnecessary many times.

Objective: We discuss the implications of ECS for preconception purposes based on our own practice.

\section{MATERIALS AND METHODS}

\section{Design: Retrospective study}

One hundred and forty-three potential gamete donors aged 20-32 years old $(\mu=24,127$ females and 16 males), signed informed consent forms and were selected according to the REDLARA guidelines (REDLARA, 2015). Blood or saliva samples were examined by one of these genetic carrier screening methods:

- Genzyme: Cystic fibrosis (CF), Spine Muscular Atrophy (SMA) and Fragile $X$ carrier tests.

- Counsyl Universal Panel: Targeted DNA mutation analysis to simultaneously determine the carrier status of an individual for 399 variants associated with 101 diseases (as of 2012).

- Recombine Carrier Map Panel: More than 981 mutations - 178 diseases (as of 2012). Panels changed over time; nowadays Carrier Map Expanded v3 is screening for 314 diseases, 302 genes, 2719 mutations (2017).

\section{RESULTS}

Genotyping results for all donors were analyzed; $41 \%$ $(58 / 143)$ of donors were identified as carriers of at least one condition. We found a carrier frequency of $6 / 143$ $(1 / 24)$ for $C F, 2 / 143(1 / 72)$ for SMA and 0/120 for Fragile $X$ syndrome. Ninety-six donors were analyzed with ECS by:

COUNSYL $(n=24): 7$ donors with 1 detected mutation: 2 with CF, 2 with Glycogen Storage Disease Type V, Alpha-1 antitrypsin deficiency, Pompe disease, Achromatopsia.

RECOMBINE $(n=72)$ : 39 were positive for at least one condition, 38 of them were a carrier of at least one high impact disease. The average carrier burden of recessive conditions was 2.1 mutations per donor (1-6). The most prevalent condition was the 5, 10 methylenetetrahydrofolate reductase (MTHRF) deficiency: $39 \%(28 / 72)$ of donors.

Results are shown in Table 1.

\section{DISCUSSION}

In 2010, a 51-year-old woman of Spanish ancestry with 16 years of infertility, 15 IUI, one GIFT, and five ICSI cycles at several fertility clinics, had a baby conceived by IVF in our clinic using mixed European ancestry donor 
Table 1. Number of gamete donors per condition.

\section{Number of gamete donors per condition} $(n=143)$

\begin{tabular}{|c|c|c|c|c|c|c|c|}
\hline & $\begin{array}{c}\text { Genzyme } \\
2010 \\
(n=47)\end{array}$ & $\begin{array}{c}\text { Counsyl } \\
2012 \\
(n=24) \\
\end{array}$ & $\begin{array}{c}\text { Recombine } \\
2012 \\
(n=72)\end{array}$ & $\mathbf{H}$ & $\mathbf{M}$ & $\mathbf{T}$ & $\mathbf{x}$ \\
\hline Cystic fibrosis & 4 & 2 & 0 & $x$ & & $x$ & \\
\hline Fragile $X$ syndrome & 0 & & 0 & $x$ & & & $x$ \\
\hline Spine muscular atrophy & 2 & 0 & 0 & $x$ & & & \\
\hline $\begin{array}{l}\text { 21-Hydroxilase-Deficient Congenital } \\
\text { Nonclasical Adrenal Hyperplasia }\end{array}$ & & & 9 & & $x$ & $x$ & \\
\hline Achromatopsia & & 1 & 1 & & & & \\
\hline Alpha-1-antitrypsin deficiency & & 1 & 2 & & $x$ & & \\
\hline Autosomal Recessive Kidney Disease & & & 1 & & & & \\
\hline $\begin{array}{l}\text { Autosomal Recessive Polycystic Kidney } \\
\text { Disease }\end{array}$ & & 0 & 2 & $x$ & & & \\
\hline Bartter Syndrome: Type 4A & & & 1 & $x$ & & $x$ & \\
\hline Biotinidase Deficiency & & 1 & 3 & $x$ & & $x$ & \\
\hline $\begin{array}{l}\text { Carnitine Palmitoyltransferase II } \\
\text { Deficiency }\end{array}$ & & 0 & 1 & $x$ & & $x$ & \\
\hline Cystinuria: No Type 1 & & & 1 & $x$ & & $x$ & \\
\hline Duarte Galactosemia & & & 2 & & & & \\
\hline Factor $\mathrm{V}$ Leiden thrombophilia deficiency & & & 2 & & & & \\
\hline Factor $\mathbf{V}$ deficiency & & & 6 & & & & \\
\hline Familial Mediterranean fever & & 0 & 2 & $x$ & & $x$ & \\
\hline $\begin{array}{l}\text { Glucose-6-Phosphate Dehydrogenase } \\
\text { Deficiency }\end{array}$ & & & 2 & & $x$ & $x$ & $x$ \\
\hline Glutamic Acidemia: Type I & & & 1 & $x$ & & $x$ & \\
\hline Glycogen Storage Disease Type V & & 2 & 0 & & $x$ & & \\
\hline Glycogen Storage Disease: Type IV & & & 1 & $x$ & & & \\
\hline $\begin{array}{l}\text { Hemochromatosis: Type 1: HFE } \\
\text { Related }\end{array}$ & & & 6 & $x$ & & $x$ & \\
\hline $\begin{array}{l}\text { Homocystinuria Caused by CBS } \\
\text { Deficiency: B6 Responsive }\end{array}$ & & 0 & 3 & $x$ & & $x$ & \\
\hline Leber Amaurosis & & & 2 & $x$ & & & \\
\hline MTHFR Deficiency & & & 28 & $\mathrm{x}$ & & $\mathrm{x}$ & \\
\hline $\begin{array}{l}\text { Nonsyndromic hearing loss and } \\
\text { Deafness }\end{array}$ & & & 2 & $x$ & & & \\
\hline Phenylalanine Hydroxylase Deficiency & & & 1 & $\mathrm{x}$ & & $x$ & \\
\hline POLG Related Disorders & & & 1 & $x$ & & & \\
\hline Pompe Disease & & 1 & & & & & \\
\hline Pseudocholinesterase Deficiency & & 0 & 1 & & $x$ & $x$ & \\
\hline Short Chain Acyl-CoA & & 0 & 7 & & $x$ & $\mathrm{x}$ & \\
\hline $\begin{array}{l}\text { Sulfate Transporter-related } \\
\text { Osteochondrodysplasia }\end{array}$ & & 0 & 1 & $x$ & & & \\
\hline Tyrosinemia: Type 1 & & 0 & 1 & $x$ & & & \\
\hline Sickle Cell Anemia & & & 1 & $x$ & & & \\
\hline
\end{tabular}

\section{* According to Recombine classification:}

H: High impact, significant effect on life expectancy and quality of life.

M: Moderate impact, do not affect life expectancy but can affect the quality of life.

T: Treatment benefits, can lessen the impact of these diseases, especially with early intervention

X: X-linked diseases are passed down by female carriers. Carriers may have symptoms.

Blank cells indicate that condition was not screened for. 
semen and oocytes from a 20-year-old donor of Italian and Spanish ancestry. Both donors had normal karyotypes. The donor semen screened negative as a carrier for CF and hemoglobinopathies.

At 10 months of age, the baby was unable to sit, stand, or crawl due to muscle weakness. The clinical diagnosis was SMA, a progressive neuromuscular disease that results in muscle weakness due to deterioration and loss of the anterior horn cells. It is inherited in an autosomal recessive manner due to mutations in the SMN1 gene. In the most common and severe form, SMA type 1, death occurs due to respiratory failure before 2 years of age. Carrier screening for SMA performed on both donors after baby diagnosis, confirmed that they carried a copy of the SMN1 deletion mutation. The child death occurred due to respiratory failure before reaching 2 years of age (Callum et al., 2010). The incidence of SMA is approximately 1 in 6,000 to 1 in 10,000 live births, and the disease is reported to be the leading genetic cause of infant death ('Committee Opinion No. 691: Carrier Screening for Genetic Conditions', 2017). It is a rare but high impact disease, due to the early onset of symptoms, significant suffering, and lack of available treatment (Callum et al., 2010).

In 2010, when the IVF treatment was done, ASRM and REDLARA had established guidelines for minimum genetic screening for gamete donor applicants (1); however, SMA carrier screening was not included. General population carrier screening for SMA was controversial due to conflicting guidelines by the ACMG (2008) and by the ACOG at the time (2009) (Callum et al., 2010).

Since gametes from an individual donor may be used by several recipients, there is an increased risk for autosomal recessive disease in the offspring due to multiple pairings, compared to the risk to offspring from a single couple. Therefore, the screening of genetic diseases for gamete donors is part of the necessary studies to reduce the risk to children born from gamete donor treatments. Hence, we decided to screen potential donors for common and severe disorders such as SMA, CF, and Fragile X (at Genzyme), routinely.

Several months later, Counsyl made the prospect of universal carrier testing feasible for the first time with a non-invasive, saliva-based assay, for more than 100 Mendelian diseases across all the main ethnic groups. The test was validated with a median of 147 positive and 525 negative samples per variant, demonstrating a multiplex assay which performance was compared with previous blood-based single-gene carrier tests. Consequently, we decided to replace the blood based gene-by-gene tests we were performing at Genzyme for the non-invasive, single test for hundreds of severe mutations at Counsyl (at the same cost) (Srinivasan et al., 2013).

In 2012, Recombine offered Carrier Map Panel to screen for a much wider range of Mendelian diseases. Therefore, we decided to screen our gamete donors and patients with their panel. This test was designed with input from professional societies worldwide and covers the widest range of ancestries. A large proportion of the population in Venezuela are multi-ethnic, they do not know their ancestry, or identify with a particular ethnicity. Carrier Map includes conditions that are common in Latin America and includes all ACOG- and ACMG-recommended conditions plus over 300 others.

\section{Carrier rate and most prevalent conditions}

The rate of donors identified as carriers for at least one condition was $41 \%(58 / 143)$. This carrier rate was surprisingly high compared with that reported for Hispanic population $(9.8 \%)$ in a study on $400+$ causal Mendelian variants from an ethnically diverse clinical sample of 23,453 individuals: carrier frequencies for self-reported ethnicity, ranged from $43.6 \%$ of Ashkenazi Jewish to $8.5 \%$ of East Asian (Lazarin et al., 2013a).

Our early results showed a high prevalence for CF and SMA among donors, compared to the one reported for the Hispanic population, as our sample sizes increased, prevalence became more similar to those reported for Hispanic, Caucasian (ACOG, 2017a) and Argentinian (Quinteiro Retamar, 2015) populations. Venezuela is a multi-ethnic society (with Spanish, Italian, Portuguese, African, and Native American backgrounds). Our donors were not randomly selected; we chose donors physically similar to our patients. The two SMA carriers were sisters and had Italian and Spanish ancestry. These results stress the need to increase sample size screening (Table 2).

Disease severity is a key criterion to include a condition in the screening panels (Grody et al., 2013; Lazarin et al., 2014). Systematic classifications of disease severity of ECS have been proposed (Lazarin et al., 2014) (Table 1). The high-impact, most prevalent conditions in our study (Carrier Map group) were: 21-Hydroxilase-Deficient Congenital Nonclassical Adrenal Hyperplasia (1/8), Factor V deficiency (1/12), Hemochromatosis: Type 1: HFE Related (1/12), Short Chain Acyl-CoA (1/14) and MTHFR deficiency $(1 / 3)(39 \%)$. It has been reported that approximately $20-$ $40 \%$ of Caucasian or Hispanic individuals are heterozygous for MTHFR C677T in the US (Levin \& Varga, 2016; Botto \& Yang, 2000).

Most data available in the literature are for US Hispanics, information for Latin-American populations are scarce. To determine the diseases with the highest carrier frequency for Latin-American populations could help to customize screening panels.

\section{Benefits of ECS}

Patients benefit from ECS by increasing their reproductive options: matching for carrier status, using gametes from an alternative donor, preimplantation genetic diagnosis, embryo donation, or even choosing a lifestyle without children. (Callum et al., 2010) ECS would also reduce the risk for autosomal recessive diseases due to multiple pairings by gamete donation.

\section{Access}

The low cost of ECS panels is one reason to support this practice. However, the actual costs of ECS need to

Table 2. Prevalence of relevant conditions comparison among our population and other reports.

\begin{tabular}{|c|c|c|c|c|c|c|}
\hline & $\begin{array}{l}\text { Genzyme. } \\
\text { Early results } \\
(n=47)\end{array}$ & All donors & $\begin{array}{c}\text { General } \\
\text { (ACOG 2017a) }\end{array}$ & $\begin{array}{c}\text { Hispanic } \\
\text { (ACOG 2017a) }\end{array}$ & $\begin{array}{l}\text { Caucasian } \\
\text { (ACOG 2017a) }\end{array}$ & $\begin{array}{c}\text { Argentinian } \\
\text { (Quinteiro } \\
\text { Retamar et } \\
\text { al., 2015) }\end{array}$ \\
\hline CF & $1: 12$ & $1: 24(6 / 143)$ & - & $1: 58$ & $1: 25$ & $1: 19$ \\
\hline SMA & $1: 24$ & $1: 72(2 / 143)$ & - & $1: 117$ & $1: 35$ & $1: 23$ \\
\hline Fragile $X$ & $0: 47$ & $0: 120$ & $1: 259$ & - & - & - \\
\hline
\end{tabular}


be carefully examined. In Latin American countries, the cost of genetic carrier screening tests remains high and can result in inequitable distribution of reproductive rights of genetic testing and services. If patients believe that screening is a must, but it is not affordable to them, the situation could create unnecessary anxiety. Counseling costs should be considered.

Research and new developments will lower costs. In the long term, it could benefit social security programs because genetic disease prevention will diminish the healthcare burden to the state. Meanwhile, governments have the opportunity-and the responsibility-to close such gaps in reproductive health, providing coverage and access to ECS services.

\section{Psychosocial implications}

ECS panels are often marketed directly to patients (Dondorp et al., 2014). Geneticists worry that this is causing unnecessary testing and misconceptions. Lack of counseling could cause anxiety or alarm, or a wrong belief that ECS would warranty the birth of a healthy child.

Some conditions are rare or do not cause significant health impairment. Disorders to be included in ECS panels should be of a nature that most patients would consider having a prenatal diagnosis to facilitate making decisions around reproduction (Grody et al., 2013). But, a study reported that ECS affected clinical decision making for patients in only $0.21 \%$ of cases: in 8 of 3,738 couples, both members were positive for the same genetic disorder or had a test result indicating that they were at risk of having an affected baby (Franasiak et al., 2016).

Genetic testing may not reveal actionable information. If a woman tested positive for a condition, should we test her partner? What would we do with this info? Should we encourage taking the risk of CVS/amniocentesis or consider pregnancy termination based on positive carrier status in both partners? It is likely to cause anxiety for patients who don't understand why you tested them for these things if you cannot recommend doing anything further (Callum et al., 2010; Grody et al., 2013).

Psychosocial implications of ECS have been studied. A meta-analysis of long- and short-term effects demonstrated that anxiety was overruled by knowledge of reproductive options and may be calmed by counseling services. Guilt was significantly associated with individuals who knew their carrier status after they had an affected child ("survivor guilt") (Lazarin et al., 2013b). Benefits of testing more often outweigh the risks, and the effects of not testing mean greater psychosocial risks (Lazarin et al., 2013b).

Counselors should know the complexity of psychosocial experiences experienced by individuals and try to address misconceptions related to the carrier status and results warranty. Some patients manage anxiety through threat minimization as an active coping mechanism. Counselors should make certain that those who appear to be managing well, will not minimize their threat and therefore neglect to take preventive actions (Lewis et al., 2011).

It is ethical to provide patients the opportunity to get the information about theirs or the donor genetic carrier status and appropriate counseling. Patients are able to evaluate complex information and take the best decisions based on their own values.

\section{Appropriate counseling and informed consent}

Fertility centers have a duty to transfer the information to patients and to reduce the psychosocial impact of ECS (Grody et al., 2013). To provide appropriate counseling to the patients, the education of health providers and psychologist is a need. Increased attention should be given to informing them about the test availability, diseases prevalence, reproductive options, residual risk, benefits, and limitations, of ECS for themselves and gamete donors. ACOG recommendations for counseling on genetic testing and communication of genetic test results has been published recently (ACOG, 2017c). ECS should only be performed after appropriate counseling and informed consent. From a clinical ethics perspective, informed consent is a communication process, and should not only be treated as a required form for the patient's signature. To prevent conflicts, it would aid implementation of generic informed consent as suggested by ACMG (Grody et al., 2013).

\section{Legal considerations for conflict prevention}

There are two primary causes of potential civil actions against healthcare providers for conflicts resulting from healthcare: lack of informed consent, and violation of the standard of care. Because of it, we recommend appropriate patient counseling and informed consent but also the education of legal professionals, based on scientific evidence. Setting appropriate medico-legal standards regarding what can be expected from centers in terms of donor's genetic testing and which test could be offered is recommended (Dondorp et al., 2014).

Legal professionals must be made aware that screening panels change over time as science advances and tests for other disorders are developed. Guidelines regarding ethnicity and population-based genetic screening are frequently updated by genetic associations. Donors could only be evaluated by the current tests recommended at the time of the donation.

Legal professionals are urged to increase their knowledge of genetic screening terminology and consider that residual risk is always present. If one partner is found to be a carrier and the other has a negative result for the same condition, the probability that the couple will have an affected pregnancy is significantly reduced, but a negative screen does not eliminate risks to offspring. The partner is unlikely to have a mutation for the same disorder, but a residual risk persists. According to most guidelines, no further testing is needed; prenatal diagnosis is not indicated. Carrier screening will not identify all individuals who are at risk of the screened conditions and some cases can be the result of a new gene mutation. It is crucial to understand that ECS is a risk reducing rather than a risk eliminating opportunity (Srinivasan et al., 2013).

\section{CONCLUSIONS}

- The rate of gamete donors identified as carriers for at least one condition was $41 \%$, which supports the provision of ECS to our population. More studies with ECS in Latin American populations could help to customize screening panels.

- The ART patient population has a unique opportunity to be offered ECS and appropriate counseling, to make its best-informed decisions.

- To provide appropriate counseling health care provider's education is a need.

- To prevent conflicts, it would be beneficial to implement generic informed consent forms.

- Legal professionals are urged to increase their knowledge of genetic screening terminology, and consider that residual risks are always present. ECS is a risk reducing rather than a risk eliminating opportunity.

- We should promote universal access to ECS. This is just the beginning of genetic applications to reproductive care. 


\section{CONFLICT OF INTEREST}

No conflict of interest has been declared.

\section{Corresponding author:}

María Teresa Urbina

Unifertes Fertility Unit

Caracas, Venezuela.

E-mail address: mturbina@unifertes.com

\section{REFERENCES}

ACOG - American College of Obstetricians and Gynecologists. Committee Opinion No. 690 Summary: Carrier Screening in the Age of Genomic Medicine. Obstet Gynecol. 2017a;129:595-6.

ACOG - American College of Obstetricians and Gynecologists. Committee on Genetics. Committee Opinion No. 691: Carrier Screening for Genetic Conditions. Obstet Gynecol. 2017b;129:e41-55.

ACOG - American College of Obstetricians and Gynecologists. Committee on Genetics. Committee Opinion No. 693: Counseling About Genetic Testing and Communication of Genetic Test Results. Obstet Gynecol. 2017c;129:e96-101.

Botto LD, Yang Q. 5,10-Methylenetetrahydrofolate reductase gene variants and congenital anomalies: a HuGE review. Am J Epidemiol. 2000;151:862-77. PMID: 10791559 DOI: 10.1093/oxfordjournals.aje.a010290

Callum P, Urbina MT, Falk RE, Alvarez-Diaz JA, Benjamin I, Sims CA. Spinal muscular atrophy (SMA) after conception using gametes from anonymous donors: recommendations for the future. Fertil Steril. 2010;93:1006.e1-2. PMID: 19962137 DOI: 10.1016/j.fertnstert.2009.10.039

Dondorp W, De Wert G, Pennings G, Shenfield F, Devroey P, Tarlatzis B, Barri P, Diedrich K, Eichenlaub-Ritter U, Tüttelmann F, Provoost V. ESHRE Task Force on Ethics and Law 21: genetic screening of gamete donors: ethical issues. Hum Reprod. 2014;29:1353-9. PMID: 24859980 DOI: $10.1093 /$ humrep/deu111

Edwards JG, Feldman G, Goldberg J, Gregg AR, Norton ME, Rose NC, Schneider A, Stoll K, Wapner R, Watson MS. Expanded carrier screening in reproductive medicine-points to consider: a joint statement of the American College of Medical Genetics and Genomics, American College of Obstetricians and Gynecologists, National Society of Genetic Counselors, Perinatal Quality Foundation, and Society for Maternal-Fetal Medicine. Obstet Gynecol. 2015;125:653-62. PMID: 25730230 DOI: $10.1097 /$ AOG.0000000000000666

Franasiak JM, Olcha M, Bergh PA, Hong KH, Werner MD, Forman EJ, Zimmerman RS, Scott RT Jr. Expanded carrier screening in an infertile population: how often is clinical decision making affected? Genet Med. 2016;18:1097-101. PMID: 26938781 DOI: $10.1038 / \mathrm{gim} .2016 .8$

Grody WW, Thompson BH, Gregg AR, Bean LH, Monaghan KG, Schneider A, Lebo RV. ACMG position statement on prenatal/preconception expanded carrier screening. Genet Med. 2013;15:482-3. PMID: 23619275 DOI: $10.1038 / \operatorname{gim} .2013 .47$
Lazarin GA, Haque IS, Nazareth S, Iori K, Patterson AS, Jacobson JL, Marshall JR, Seltzer WK, Patrizio P, Evans EA, Srinivasan BS. An empirical estimate of carrier frequencies for $400+$ causal Mendelian variants: results from an ethnically diverse clinical sample of 23,453 individuals. Genet Med. 2013a;15:178-86. PMID: 22975760 DOI: 10.1038/gim.2012.114

Lazarin GA, Haque IS, Nazareth S, Evans EA. Response to Stoll and Resta. Genet Med. 2013b;15:319-20. PMID: 23552454 DOI: $10.1038 /$ gim.2013.19

Lazarin GA, Hawthorne F, Collins NS, Platt EA, Evans EA, Haque IS. Systematic Classification of Disease Severity for Evaluation of Expanded Carrier Screening Panels. PLoS One. 2014;9:e114391. PMID: 25494330 DOI: $10.1371 /$ journal.pone.0114391

Levin BL, Varga E. MTHFR: Addressing Genetic Counseling Dilemmas Using Evidence-Based Literature. J Genet Couns. 2016;25:901-11. PMID: 27130656 DOI: $10.1007 / \mathrm{s} 10897-016-9956-7$

Lewis $\mathrm{C}$, Skirton $\mathrm{H}$, Jones $\mathrm{R}$. Can we make assumptions about the psychosocial impact of living as a carrier, based on studies assessing the effects of carrier testing? J Genet Couns. 2011;20:80-97. PMID: 20878544 DOI: $10.1007 / \mathrm{s} 10897-010-9327-8$

Practice Committee of American Society for Reproductive Medicine; Practice Committee of Society for Assisted Reproductive Technology. Recommendations for gamete and embryo donation: a committee opinion. Fertil Steril. 2013;99:47-62. PMID: 23095142 DOI: $10.1016 /$ j.fertnstert.2012.09.037

Quinteiro Retamar A, Borghi CM, Fiszbajn G, Papier S, Munne S, Hamer J, Alvarez Sedo C. Genetic carrier screening in an egg donor program. Fertil Steril. 2015;104:e14-5. DOI: 10.1016/j.fertnstert.2015.07.045

REDLARA - Red Latinoamericana de Reproducción. Manual de Procedimientos Clínicos en Reproducción Asistida. Caracas: Editorial Ateproca; 2015.

Srinivasan BS, Evans EA, Flannick J, Patterson AS, Chang CC, Pham T, Young S, Kaushal A, Lee J, Jacobson JL, Patrizio P. A universal carrier test for the long tail of Mendelian disease. Reprod Biomed Online. 2013;21:537-51. PMID: 20729146 DOI: $10.1016 /$ j.rbmo.2010.05.012

Wilson RD, De Bie I, Armour CM, Brown RN, Campagnolo C, Carroll JC, Okun N, Nelson T, Zwingerman R, Audibert F, Brock JA, Brown RN, Campagnolo C, Carroll JC, De Bie I, Johnson JA, Okun N, Pastruck M, Vallée-Pouliot $\mathrm{K}$, Wilson RD, Zwingerman R, Armour C, Chitayat D, De Bie I, Fernandez S, Kim R, Lavoie J, Leonard N, Nelson T, Taylor S, Van Allen M, Van Karnebeek C. Joint SOGCCCMG Opinion for Reproductive Genetic Carrier Screening: An Update for All Canadian Providers of Maternity and Reproductive Healthcare in the Era of Direct-to-Consumer Testing. J Obstet Gynaecol Can. 2016;38:742-62.e3. PMID: 27638987 DOI: 10.1016/j.jogc.2016.06.008 